\title{
First molecular identification and phylogenetic tree of Petasiger exaeretus Dietz, 1909 (Digenea: Echinostomatidae) from an intermediate host Radix auricularia (L., 1758) in Greater Zab river, Iraq
}

\author{
Shwan Khursheed Bashê ${ }^{1, A-F}$, Luay Abdul-Qadir Ali ${ }^{1, A, F}$ \\ ${ }^{1}$ Education College, Salahaddin University, Erbil, Iraq \\ A - Research concept and design, B - Collection and/or assembly of data, C - Data analysis and interpretation, \\ $D$ - Writing the article, E - Critical revision of the article, F - Final approval of article
}

Shwan Khursheed Bashê, Luay Abdul-Qadir Ali. First molecular identification and phylogenetic tree of Petasiger exaeretus Dietz, 1909 (Digenea: Echinostomatidae) from an intermediate host Radix auricularia (L., 1758) in Greater Zab river, Iraq. Ann Agric Environ Med. $2019 ; 26(3)$ : $504-507$. doi: 10.26444/aaem/111831

\begin{abstract}
Introduction. Radix auricularia (Linnaeus, 1758) is a freshwater gastropod belongs to the Lymnaeidae (pond snails) family which act as intermediate hosts or vectors of various parasitic flukes. No study has yet been undertaken on the prevalence of Petasiger spp. infection in R. auricularia. Species of Petasiger (Dietz, 1909) are a cosmopolitan parasite that utilize snails as the first intermediate host, with vertebrates like amphibians larvae and fish as the second intermediate host, followed by fish-eating birds. The current paper is considered to be the first report of Petasiger exaeretus parasitized $R$. auricularia in Iraq, which is supported with molecular and phylogenetic analysis.

Materials and method. Freshwater snails R. auricularia were collected during October 2016 - September 2017 from different locations of Sufaia village on the Greater Zab river, Erbil province, Iraq.

Results. A total of 307 freshwater snails $R$. auricularia were collected, only five of them were infected with a prevalence of Petasiger exaeretus (1.62\%).

Conclusions. The current study agrees with the opinion of Selbach, Soldánová (26), which suggested the possibility of a much higher morphological diversity within Petasiger species, based on the number of described cercariae, compared with adult forms.It is clear that $P$. phalacrocoracis specimens have often been erroneously designated as $P$. exaeretus by many authors (Našincová et al., 1994). Certain morphological similarities and dissimilarities between $P$. exaeretus and $P$. phalacrocoracis can be detected: the pear-shaped body resembles $P$. exaeretus, whereas, $P$. phalacrocoracis have an elongated body.
\end{abstract}

Key words

Petasiger, Cercariae, Radix, Snail, Iraq

\section{INTRODUCTION}

Radix auricularia (Linnaeus, 1758) is a freshwater gastropod belonging to the family of Lymnaeidae (pond snails) which act as intermediate hosts or vectors of various parasitic flukes. This snail favours inhabiting stagnant, slow flowing water heavy with vegetation $[1,2]$. At least 71 species of digenetic trematodes belonging to 13 families use this species as obligatory intermediate host in their life cycle, which can cause severe debilitating pathogenicity in many hosts, for instance, parasitized on birds and mammals as definitive hosts [3, 4]. In Iraq, different species of Lymnaeid snails were recorded, the most important being Radix auricularia (Eared pond snail), numerous investigations have been carried out on the abundance of cercariae infection and diversity in Lymnaeid snails, particularly $R$. auricularia, among them: [5-12]. To our knowledge, no study has yet been undertaken on the prevalence of Petasiger species infection in $R$. auricularia.

Address for correspondence: Shwan Khursheed Bashê, Education college, Salahaddin University, Erbil, Iraq

E-mail: shwan.raman@su.edu.krd

Received: 15.06.2019; accepted: 19.08.2019; first published:09.09.2019
Species of Petasiger (Dietz, 1909) are a cosmopolitan parasite that utilizes snails as the first intermediate host and vertebrates, like amphibian larvae and fish as the second intermediate host, followed by fish-eating birds (cormorants, grebes, herons, etc.) as a final host, occurring usually in the Palearctic region $[13,14,15]$. The main diagnostic features for identifyinjg Petasiger among species are the number of collar spines, and the arrangement for adult and developing stages. The numbers range between 19-27 with lateral and dorsal spines in a single row, and two groups of 3-4 angle spines which are longer than the lateral spines [16]. This constitute a relatively 33 nominal species $(23$ species recorded from the Palaearctic) and the most recent revision based on a comparative morphological study of the genus recognized a total of 18 valid species [17]. Seven species have been recorded in Europe: two species possessing 27 collar spines Petasiger exaeretus (Dietz, 1909) and Petasiger phalacrocoracis (Yamaguti, 1939) and five species with 19 collar spines ( $P$. grandivesicularis Ishii, 1935, $P$. islandicus Kostadinova and Ski'rnisson, 2007, P. megacanthus (Kotla'n, 1922), P. neocomense Fuhrmann, 1927 and $P$. pungens (Linstow, 1893) [16]. In addition, it can be difficult to identify the infection at the species level using these methods, since the larval morphology is similar to each other [18]. 
Consequently, molecular approaches have been applied for accurate identification of the parasite at larval stages [19].

Despite the diversity of species of Petasiger in Europe and North America, only two species have been identified in birds from South America: P. novemdecim (Lutz, 1928), $P$. argentinensis (Lunaschi and Drago, 2010)) described in both the Great Grebe, Podiceps major (Boddaert, 1783), and the White-Tufted Grebe, Rollandia rolland (Quoy and Gaimard, 1824) in Argentina [16]. In addition, two undetermined species of Petasiger were reported in Argentina: Petasiger sp. 1 and Petasiger sp. 2 [20]. Information regarding the occurrence of larval stages of Petasiger in South America is scarce [21].

Moreover, all the above-mentioned researchers indicate that this species have not recorded outside its present location. The current study is therefore considered to be the first to report of Petasiger exaeretus parasitized $R$. auricularia in Iraq, which is supported by molecular and phylogenetic analysis.

\section{MATERIALS AND METHOD}

Study area. The freshwater snails $R$. auricularia were collected during October 2016 - September 2017 from different locations of Sufaia village on the Greater Zab river, Erbil Province, Iraq (36 $\left.11^{\prime} 49.3^{\prime \prime N} 43^{\circ} 35^{\prime} 02.8^{\prime \prime} \mathrm{E}\right)$. The snails were examined for cercariae infection (Fig. 1).

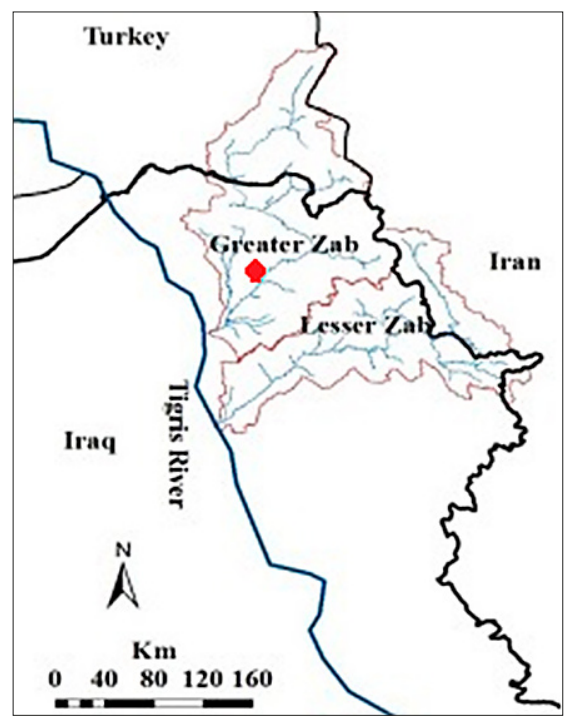

Figure 1. Map of Greater Zab river in north Iraq showing the studied area

Collection of Lymnaeid snails and digenean cercariae identification. The collected $R$. auricularia snails were kept in a plastic screw-capped container supplied with water from their habitat, then directly transferred to the Advanced Parasitology Laboratory. The species were identified by using an identification key [22]. The snails were kept alive in an aquarium with optimal temperature and $\mathrm{O}_{2}$ pressure to study cercariae infection [23]. In order to isolate the larval trematodes from snails, a conventional method was used to examine cercarial infections by exposing the snails to light (shedding) and/or by dissection (Rediae were obtained by crushing infected snails between glass slides). The snails were individually placed in glass Petri-dishes containing $50 \mathrm{ml}$ dechlorinated tap water. Each Petri-dish was lit for 4-6 hrs. with a 100-W light bulb at a distance of $15 \mathrm{~cm}$ to increase water temperature and induce the expulsion of cercariae. If no cercariae shedding observed, snails were crushed under a stereomicroscope by forcep in order to find immature cercariae, sporocyst and/or redia. Cercariae or other stages were fixed in $70 \%$ molecular grade ethanol for DNA extraction and sequencing.

DNA extraction and $28 \mathrm{~S}$ amplification. DNA was extracted from the redia and cercariae isolated from the snails, preserved in ethanol and centrifuged at 8,000 RPM for 5 min.; the ethanol was then removed. The DNA was extracted using a PrimePrep TM Genomic DNA Extraction Kit (GeNetBio, Korea) according to the manufacturer's instructions. Quantification of DNA concentration was performed by using NanoDrop (ND-1000, USA). An area of $28 \mathrm{~S}$ rDNA was amplified by applying a universal primer which expected to be specific to Platyhelminthes. The forward primer C1 (ACCCGCTGAATTTAAGCAT at position 25), and the reverse primer C3 (CTCTTCAGAGTACTTTTCAAC at position 390), which were designed by [24]. The expected size of PCR product was 365 bps. A standard PCR reagent was used (One PCRPTMP master mix, GeNetBio, Korea). The PCR mixture $(20 \mu \mathrm{l})$ contained: $10 \mu \mathrm{l}$ master mix, 1.5 $\mu \mathrm{l}$ of each of the 2 primers, $2 \mu \mathrm{l}$ DNA template and $5 \mu \mathrm{l}$ double-demonized water $\left(\mathrm{ddH}_{2} \mathrm{O}\right)$. PCR was performed in a MJ Research, Applied Biosystem (AB) thermocycler under the following conditions: $94 \mathrm{C}^{\circ} / 5 \mathrm{~min} ; 35$ cycles of $94 \mathrm{C}^{\circ} / 45$ sec; $50 \mathrm{C}^{\circ} / 45 \mathrm{sec} ; 72 \mathrm{C}^{\circ} / 45 \mathrm{sec}$, followed by one cycle of 72 $\mathrm{C} \% \mathrm{~min}$. PCR products were resolved in $2 \%$ agarose gel stained with Safe dye or ethidium bromide for UV light visualization of DNA. DNA sequencing was performed using forward primer of DNA amplicons by using ABI 3730XLs nucleotide sequence analyzer (Macrogen-Korea). The evolutionary history was inferred by applying the Maximum Likelihood method based on the Jukes-Cantor model [25]. The percentage of trees in which the associated taxa clustered together is shown next to the branches. Initial tree(s) for the heuristic search were obtained automatically by applying Neighbor-Join and BioNJ algorithms to a matrix of pairwise distances estimated using the Maximum Composite Likelihood (MCL) approach. The tree is drawn to scale, with branch lengths measured in the number of substitutions per site. The analysis involved 12 nucleotide sequences. All positions containing gaps and missing data were eliminated. There was a total of 333 positions in the final dataset. Evolutionary analyses were conducted in MEGA7 [26].

\section{TAXONOMIC}

Evaluation analysis assisted in classifying the trematodes as:

Family Echinostomatidae Loss, 1899.

Subfamily Echinostomatinae Loss, 1899.

Genus Petasiger Dietz, 1909.

Petasiger exaeretus Dietz, 1909.

Syn. P. baschkirovi Ablassov and Iksanov, 1958 


\section{RESULTS}

A total of 307 freshwater snails $R$. auricularia were collected, only 5 of which were infected with Petasiger exaeretus, with a prevalence (1.62\%). The examined parasite includes redia (mother and daughter) and cercariae. The Blast result in GenBank of DNA (28S rDNA) sequence of Petasiger exaeretus indicated 99\% similarity to this species with Accession No. KT956923.1) (Fig. 2).

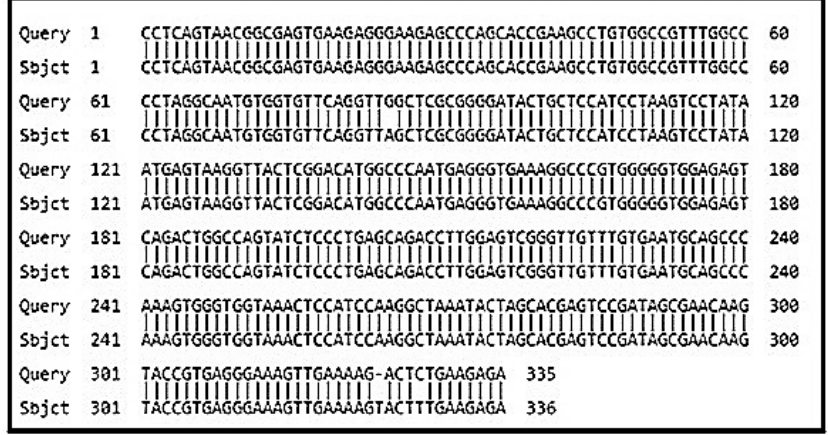

Figure 2. Pairwise alignment of 28S rDNA sequence of Petasiger exaeretus. Query is the study or sample sequence and Subject is the GenBank sequence.

\section{DISCUSSION}

Genus Petasiger was first named by Dietz in 1909. Members of this genus are common parasites of fish-eating birds and few others. The genus was previously reported in Europe, Asia, America, Africa and Australia [14, 17]. Petasiger exaeretus Dietz, 1909, is commonly found in birds belonging to the family Phalacrocoracidae [27]. The result obtained showed a 99\% similarity to the partial $28 \mathrm{~S}$ rDNA region of sporocyst, redia and cercaria sequences of $P$. exaeretus isolated from the Radix auricularia freshwater snail, recorded in Ukraine (KT956923.1) [28] and Hungary (KY284001.1- KY284007.1) [29] (Fig. 3), and were identical or nearly identical with the deposited sequences of P. phalacrocoracis (KY283999.1) described by Tkach, Kudlai [28], P. phalacrocoracis (KT956926.1) and Paryphostomum radiatum (KT956927.1) by Cech, Molnár [29]. Sequences of $P$.

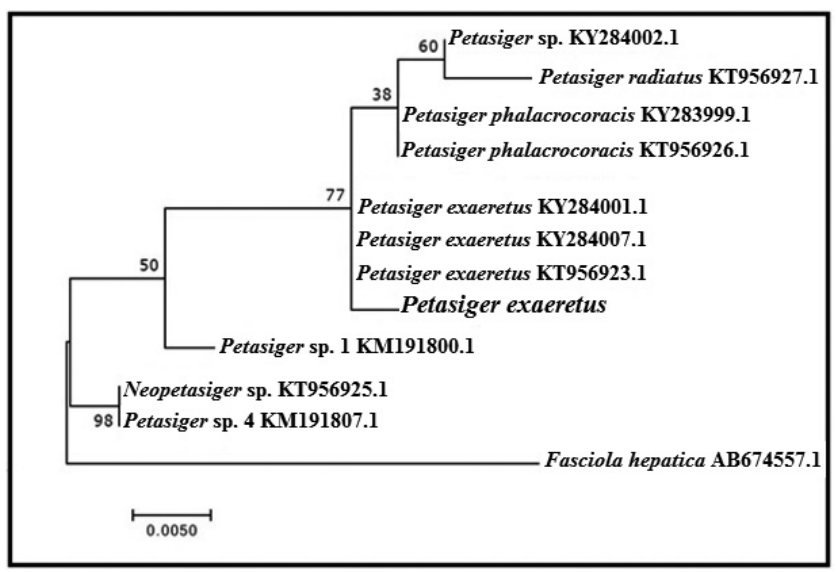

Figure 3. Maximum Likelihood tree 28S rDNA of the P. exaeretus isolated in Lymnaed auricularia in relation to echinostomid deposited in GenBank. The percentage of trees in which the associated taxa clustered together is shown next to the branches. The tree is drawn to scale, with branch lengths measured in the number of substitutions per site. All positions containing gaps and missing data were eliminated. There was a total of 333 positions in the final dataset. Evolutionary analyses were conducted in MEGA7 (Kumar et al., 2016). exaeretus with $P$. phalacrocoracis, $P$ a. radiatum did not match any of them and these differences can be attributed to host ecology and geography [29].

It is clear that $P$. phalacrocoracis specimens have often been erroneously designated by many authors as $P$. exaeretus [13]. Certain morphological similarities and dissimilarities between $P$. exaeretus and $P$. phalacrocoracis can be detected: the pear-shaped body resembles $P$. exaeretus, whereas $P$. phalacrocoracis have an elongated body. However, present trematodes closely resemble $P$. exaeretus, with slight variations [27]. Neopetasiger (KT956925.1) by Tkach, Kudlai [28], Petasigr sp. 4 (KM191807.1) by Selbach, Soldánová [30], which represent a molecular difference from the results of the current study, and dissimilarity with the outline specimen Fasciola hepatica (AB674557.1) [31]. Tkach, Kudlai [28], also proposed that $\mathrm{Pa}$. radiatum should be transferred from the genus Paryphostomum to Petasiger. The current study agrees with the opinion of Selbach, Soldánová [30], which suggested the possibility of presenting a much higher morphological diversity within Petasiger species, based on the number of described cercariae, compared with adult forms. There are other Petasiger species described in Europe [32] for which their sequence data are not yet available, including $P$. grandivesicularis Ishii, 1935, P. megacanthus (Kotlán, 1922) and P. pungens (Linstow, 1893). Faltýnková, Gibson [17]\{Faltýnková, 2008 \#163;Faltýnková, 2008 \#163\} considered $P$. caribbensis, $P$. novemdecim P. tientsinensis and $P$. baschkirovi as synonymous of $P$. exaeretus. Recently, 2 studies used molecular markers on species of the Petasiger [33], and recorded 4 new cercariae of Petasiger species based on morphological and $28 \mathrm{~S}$ rDNA, and nadI sequence analysis. Recently, using the $28 \mathrm{~S}$ rDNA sequence, a full molecular phylogeny of Echinostomatoidea Looss, 1899, have been provided that involvedthe Petasiger species. In platyhelminth systematics, rDNA genes, in general, have been used successfully and $28 \mathrm{~S}$ rDNA, in particular, to value the relationships existing among the Platyhelminthes [34].

\section{Acknowledgement}

The authors would like to thank Sarwat Al-Qassab, PhD (Molecular Biology, Biotechnology and Parasitology. University of Technology, Sydney, Australia) and Sardar S. Karash, PhD (Cell and Molecular Biology Program, University of Arkansas, Fayetteville, AR, USA), lecturers in the Biology Department of Salahaddin University Iraq.

\section{REFERENCES}

1. Sharif M, Daryani A, Karimi S. A faunistic survey of cercariae isolated from lymnaeid snails in central areas of Mazandaran, Iran. Pakistan J Biol Sci. 2010; 13(4):158.

2. Imani-Baran A, Yakhchali M, Malekzadeh Viayeh R, Farhangpajuh F. Prevalence of Cercariae Infection in Lymnaea auricularia (Linnaeus, 1758) in NorthWest of Iran. J Pajouhesh va Sazandegi 2011; 2(2):121-7.

3. Chontananarth T, Wongsawad C. Prevalence of Haplorchis taichui in field-collected snails: a molecular approach. Korean J Parasitol. 2010; 48(4):343.

4. Brown D. Pulmonate molluscs as intermediate hosts for digenetic trematodes. Pulmonates. 1978; 2:287-333.

5. Al-Abbad M, Al-Ali A, Al-Mayah S. Cercarial production of Lymnaea auricularia experimentally infected with different numbers of Fasciola gigantica Miracidia. Mesopotamian J Marine Sci. 2005; 20(1):1-6.

6. Al-Kubaisee R, Altaif K. Comparative study of sheep and buffalo isolates of Fasciola gigantica in the intermediate host Lymnaea auricularia. Res Vet Sci. 1989; 47(2):273-4. 
7. Al-Habbib W, Al-Zako S. The effect of different temperatures on the development of intra-molluscan stages of Fasciola gigantica. J Ther Biol. 1981; 6(4):373-7.

8. Al-Asadi S. Effect of calcium chloride on hatching, growth and survival of snails Lymnaea auricularia-Intermediat host of Fasciola gigantica. Marsh Bulletin. 2011; 6(2):125-33.

9. Ismael IW, Abdullah HN, Al-Azizz SA. Molecular Diagnosis of Ornethobilharzia Turkestanicum in Maysan Province-Iraq. Iraqi J Biotechnol. 2017; 16(1):53-60.

10. Al-Waaly ABM, Al-Mayali HMH, Mohammad MK. Moleculare identification of giant liver fluke Fasciola gigantica from intermediate host snail Radix sp. in middle and south of Iraq. Al-Qadisiyah J Pure Sci. 2015; 20(1): 24-9.

11. Hussein A-NA, Khalifa R. Experimental infections with Fasciola in snails, mice and rabbits. Parasitol Res. 2008; 102(6):1165-70.

12. Kuchai J, Tak H, Chishti M, Rasool M, Dar S, Ahmad J. Impact of season, sex, age, and agro-ecology on the prevalence of fascioliasis in buffalos of Ladakh. Online J Animal Feed Res. 2011; 1(6):263-6.

13. Našincová V, Scholz T, Moravec F. Redescription of Petasiger exaeretus Dietz, 1909 and P. phalacrocoracis (Yamaguti, 1939)(Trematoda: Echinostomatidae), parasites of cormorants. Systematic Parasitol. 1994; 27(2):139-47.

14. Zamparo D, Overstreet RM, Brooks DR. A new species of Petasiger (Digenea: Echinostomiformes: Echinostomatidae) in the Brown Pelican, Pelecanus occidentalis,(Aves: Pelecaniformes: Pelecanidae), from the Area de Conservación Guanacaste, Costa Rica. J Parasitol. 2005; 91(6):1465-7.

15. Fried B, Toledo R. The biology of echinostomes: from the molecule to the community: Springer Science \& Business Media; 2009.

16. Lunaschi L, Drago F. A new species of Petasiger (Digenea, Echinostomatidae) parasitizing Podiceps major and Rollandia rolland (Aves, Podicipedidae) from Buenos Aires Province, Argentina. Acta Parasitol. 2010; 55(3):230-4.

17. Faltýnková A, Gibson DI, Kostadinova A. A revision of Petasiger Dietz, 1909 (Digenea: Echinostomatidae) and a key to its species. Systematic Parasitol. 2008; 71(1):1.

18. Chontananarth T, Thanawan Tejangkura NW, Chimburut C. Morphological characteristics and phylogenetic trends of trematode cercariae in freshwater snails from Nakhon Nayok Province, Thailand. Korean J Parasitol. 2017; 55(1):47.

19. Jousson O, Bartoli P, Pawlowski J. Molecular identification of developmental stages in Opecoelidae (Digenea) 1. Internat J Parasitol. 1999; 29(11):1853-8.

20. Drago FB, Lunaschi LI. Digéneos parásitos de aves Ciconiiformes de Argentina. Revista mexicana de biodiversidad. 2011; 82(1):77-83.
21. Pinto HA, Mahecha GAB, de Melo AL. Petasiger Dietz, 1909 (Trematoda: Echinostomatidae) in Birds and Mollusks from Brazil. Revista Brasileira de Parasitologia Veterinária. 2013; 22(3):427-32.

22. Mansoorian A. Freshwater Gastropod of Khuzestan Province, SouthWest Iran. Iranian Internat J Sci. 2001; 2(2):96-103.

23. Ataev G, Prokhorova E, Kudryavtsev I, Polevshchikov A. The influence of trematode infection on the hemocyte composition in Planorbarius corneus (Gastropoda, Pulmonata). Invertebrate Survival J. 2016; 13(1):164-71.

24. Mollaret I, Jamieson BG, Justine J-L. Phylogeny of the Monopisthocotylea and Polyopisthocotylea (Platyhelminthes) inferred from 28S rDNA sequences1. Int J Parasitol. 2000; 30(2):171-85.

25. Jukes TH, Cantor CR. Evolution of protein molecules. Mammalian protein metabolism. 1969; 3(21):132.

26. Kumar S, Stecher G, Tamura K. MEGA7: molecular evolutionary genetics analysis version 7.0 for bigger datasets. Molecular Biol Evolution. 2016; 33(7):1870-4.

27. Abro MM, Dharejo AM, Khan MM, Ali N, Birmani SN. Description of first record of Petasiger exaeretus Dietz, 1909 (Trematoda: Echinostomatidae) in avian host from Pakistan. Punjab University J Zooloogy. 2016; 31(2):181-5.

28. Tkach VV, Kudlai O, Kostadinova A. Molecular phylogeny and systematics of the Echinostomatoidea Looss, 1899 (Platyhelminthes: Digenea). Int J Parasitol. 2016; 46(3):171-85.

29. Cech G, Molnár K, Székely C. Molecular biological studies of adult and metacercarial stages of Petasiger exaeretus Dietz, 1909 (Digenea: Echinostomatidae). Acta Veterinaria Hungarica. 2017; 65(2):198-207.

30. Selbach C, Soldánová M, Georgieva S, Kostadinova A, Kalbe M, Sures B. Morphological and molecular data for larval stages of four species of Petasiger Dietz, 1909 (Digenea: Echinostomatidae) with an updated key to the known cercariae from the Palaearctic. Systematic Parasitol. 2014; 89(2):153-66

31. Saki J, Khademvatan S, Yousefi E. Molecular identification of animal Fasciola isolates in Southwest of Iran. Australian J Basic Appl Sci. 2011; 5(11):1878-83.

32. Kostadinova A. Family Echinostomatidae. In: Jones, A., Bray, R. A. and Gibson, D. I. (eds) Key to the Trematoda. CAB International, Wallingford and The Natural History Museum, London, UK. 2005.

33. Georgieva S, Kostadinova A, Skirnisson K. The life-cycle of Petasiger islandicus Kostadinova \& Skirnisson, 2007 (Digenea: Echinostomatidae) elucidated with the aid of molecular data. Systematic Parasitol. 2012; 82(3):177-83.

34. Koyee QM, Khailany RA, Al-Marjan KS, Abdullah SM. MolecularBased Identification of Polystoma integerrimum by $28 \mathrm{~S}$ rDNA, Phylogenetic and Secondary Structure Analysis. Jordan J Biolo Sci. 2016; 9(2).

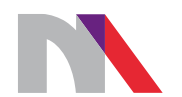

\section{Ministry of Science} and Higher Education

Republic of Poland

Generation of the DOI (Digital Object Identifier) - task financed under the agreement No. 618/P-DUN/2019 by the Minister of Science and Higher Education 